\title{
Covid-19: how coronavirus will change the face of general practice forever
}

\author{
GPs say the covid-19 pandemic will bring about lasting change in how they work, Jacqui Thornton \\ reports
}

\author{
Jacqui Thornton freelance journalist
}

London, UK

At practice level, primary care has altered dramatically in the past few weeks, with staff_clinical and administrative-adapting to new ways of working.

At some practices, entrance doors are locked shut and prescriptions given out from a window. Red tape, appraisals, and routine work has been relaxed, and home visits hugely reduced. At the end of phone and video consultations, many patients are saying "thank you and good luck."

In one practice in Hampshire, where nearly half the reception and admin staff are off work as a precaution, senior partner Alex Fitzgerald-Barron said they are as ready as possible.

"On the coal face, my whole team has given $110 \%$ : working hours have gone out the window, clinicians come in or video call on their day off, our local practices have been collaborating almost daily, and, for the stuff we can control, we feel as prepared as we can be," he told The BMJ.

Trish Greenhalgh, professor of primary care health sciences, who co-authored an article advising GPs on remote assessment for covid-19, ${ }^{1}$ said that GPs are working flat out. "They're worried about how to manage patients and also whether the personal protection equipment (PPE) they've got is adequate. They are shifting to phone and video at an unprecedented pace," Greenhalgh said.

It's a confusing situation; some practices are fired up, others are more anxious about what might happen in the coming weeks. For single-handed surgeries, and those that were already struggling before the outbreak, there is concern about how they're coping in this new world.

\section{Guidance: too little or too much?}

In early March, Nikita Kanani, NHS England's medical director for primary care, wrote to GPs recommending telephone or video triage to avoid patients coming into surgeries. ${ }^{2}$

The following week, Martin Marshall, chair of the Royal College of General Practitioners (RCGP) Council and a GP in Newham, London, said that while there was lots of information on covid-19, it was generic and didn't tackle the specific needs of primary care. "GPs are becoming increasingly desperate for the right type of information," he wrote in a blog. The RCGP published its own guidance. ${ }^{4}$

A week later Public Health England published interim guidance for primary care, ${ }^{5}$ and three days later NHS England sent out further guidance on at risk patients. ${ }^{6}$ The RCGP is now working with NHS England and accepts the body had been "inundated" with requests for further information, making it hard to respond adequately.

Rachel Hopkins, a GP based in north London, told The BMJ that she is frustrated with the lack of clear central direction, or a clinical care model, from clinical commissioning groups (CCGs). In this void, primary care networks (PCNs) have been left to make their own decisions. Others said they would like more granular detail in guidance and more local nuance as to whether they are a "hot spot" as well as when to use PPE. ${ }^{7}$ One GP told The BMJ about time consuming daily emails packed with complex protocols. But others said the situation is so unprecedented it is unfair to criticise.

\section{Local decision making on hot hubs}

In the meantime, PCNs appear to be coming into their own in the crisis, collaborating well and sharing workforce. Localised decision making is evident when it comes to the establishment of "hot hubs" (sometimes called red zones)—dedicated clinics to care for people with confirmed or suspected covid-19 infection who also need treatment for other medical problems. In this way, they will be separated from non-covid-19 patients in "cold hubs" or green zones.

In Gloucestershire, three PCNs covering 20 surgeries are taking over a dental surgery run by staff working on a rota, leaving normal surgeries as green zones. Richard Probert, clinical director of Berkeley Vale PCN, says there was a clear steer to do this from the CCG.

It began testing the model on 27 March with patients being assessed in their cars underneath a marquee by a GP in full PPE before going into the hub for treatment, if necessary. It runs a 
four hour session during normal GP opening hours Monday to Friday, with a GP, nurse, and admin staff.

Mark Porter, who works in a practice in the south of the county, describes it as "an initiative by GPs for GPs and their patients," driven by the PCNs. "We don't know how the service is going to develop or what the demand's going to be like, whether we need to open longer, whether it needs to go seven days a week. But we're up and running and ready."

\section{Urban challenges and spare capacity}

In the capital, it's a different story, with little clarity from CCGs on how to clinically assess patients. In south London, one surgery has set up a single "hot room" within the practice which is decontaminated after use.

In Islington, north London, local PCNs have identified one surgery to be turned into a hot hub, and are waiting for the current occupants to decamp before setting it up with PPE, infection control, and IT. If it works, two further sites are proposed to open a week later.

Ben Smith, chair of the Islington GP Federation, told The BMJ that it's unrealistic for GPs not to see potential covid-19 patients, particularly as the 111 system is under severe and unsustainable pressure. But, he added, "We're still waiting for a clinical model which may tell us we are going down the wrong route."

Marshall says the fact that some areas have not yet established hot hubs will not matter for long. "The differentiation between hot and cold is going to become less and less relevant as time goes on."

Hopkins said that she wished she could do more to help hospital colleagues. "We hear emergency departments are inundated and we're twiddling our thumbs. We're doing paperwork and preparing, but we have spare clinical capacity, particularly with junior colleagues."

\section{Future working}

One of the biggest changes in working practices is increased telephone and video consultations, which are proving shorter than standard ones, freeing up time. Video calls are not always suitable for patients without smartphones-home visits are still happening. But Porter says, "They have transformed our day. We're getting through things much quicker."

As well as patient contact, surgeries are using video to hold daily practice meetings with staff, and with local nursing homes. A number of tech companies, including $\mathrm{AccuRx}^{8}$ (see box) are providing video technology packages to GPs. These can be used on personal mobile devices without exposing clinicians' personal contact details.

There are, however, challenges with home working. GPs report frustrations with IT problems such as slow NHS laptops. Often their personal laptops are superior but for security reasons they can't be used for consultations because they don't allow access to the Electronic Patient Record. Proprietary software and strong firewalls can also hinder access.
This has cost implications for surgeries as they must fund compatible computers. Some GPs are throwing caution to the wind and using non-secure alternatives if the online video connection goes down during a consultation.

Some practices and CCGs are already using systems like Away From My Desk, ${ }^{9}$ which enables remote secure working, and it's understood that the tokens needed to work this are in short supply.

One consensus is that, whenever this crisis finally passes, the landscape of how GPs function will have changed forever. Lambeth GP Tom Nolan says the legacy of the pandemic may be a difference in the way that people think and act in terms of seeking help for their health.

"My hope is that some people will become more able to self-manage, particularly those with minor self-limiting problems, and that this will be an opportunity to refocus primary care away towards those with the greatest needs."

\section{The redemption of video consultations}

With covid-19, many NHS GPs who were previously sceptical about video consultations have been turned around. GP Mark Porter told The BMJ he was "gobsmacked" at how well it has worked.

One of the companies providing the platform to enable this is AccuRx, a health tech startup that already has an SMS tool used by GPs, which is integrated into EMIS and other GP record systems.

When GPs were told two weeks ago that face to face appointments needed to be replaced, the company decided to build a new video consultation service that weekend. The solution was tested on the Monday morning then enabled for 3600 practices across the country that afternoon. Since then, the number of practices using it has gone from 3600 to 5700 - over $80 \%$ of practices in the country.

South London GP Pete Deveson said he was sceptical at first but it has been "amazingly helpful."

AccuRx are now encouraging its use in secondary care. Early adopter Conor Byrne, a consultant nephrologist at Barts Health NHS Trust, says it has been helpful to check on transplantation patients in the high risk category. "They are terrified; to see they are breathing okay is extremely reassuring."

Competing interests: I have read and understood BMJ policy on declaration of interests and have no relevant interests to declare.

1 Greenhalgh T, Koh GCH, Car J. Covid-19: a remote assessment in primary care. BMJ 2020;368:m1182. 10.1136/bmj.m1182 32213507

2 NHS England and NHS Improvement. Letter to primary care. 5 March 2020. https://cached. offlinehbpl.hbpl.co.uk/NewsAttachments/PGH/Preparedness_letter_primarycare_NK_ 5March2020.pdf.

3 Royal College of General Practitioners. Covid-19 is a GP crisis too. 11 March 2020. www. rcgp.org.uk/about-us/rcgp-blog/covid-19-is-a-gp-crisis-too.aspx.

4 Royal College of General Practitioners. Novel coronavirus: RCGP guidance for genera practice (including OOH). 13 March 2020. www.rcgp.org.uk/-/media/Files/Policy/A-Zpolicy/2020/covid19/RCGP-GP-guidance-march-2020.ashx?la=en.

5 Public Health England. Guidance: covid-19: interim guidance for primary care. 19 March 2020. www.gov.uk/government/publications/wn-cov-guidance-for-primary-care/wn-covinterim-guidance-for-primary-care.

6 NHS England and NHS Improvement. Guidance and updates for GPs: at-risk patients. 26 March 2020. www.england.nhs.uk/coronavirus/publication/guidance-and-updates-forgps-at-risk-patients.

7 Newman M. Covid-19: doctors' leaders warn that staff could quit and may die over lack of protective equipment. BMJ 2020;368:m1257. 10.1136/bmj.m1257 32217522

8 AccuRx. www.accurx.com.

9 Away From My Desk. https://secure.awayfrommydesk.com.

Published by the BMJ Publishing Group Limited. For permission to use (where not already granted under a licence) please go to http://group.bmj.com/group/rights-licensing/ permissions 